\title{
Solid State Impact Welding of BMG and Copper by Vaporizing Foil Actuator Welding
}

Anupam Vivek ${ }^{1}$, Michael Presley ${ }^{1}$, Katharine M. Flores ${ }^{1,2}$, Nicholas H. Hutchinson ${ }^{1}$, Glenn S. Daehn ${ }^{1}$

${ }^{1}$ Dept. of Materials Science and Engineering, The Ohio State University, 2041 College Road, Columbus, $\mathrm{OH}, 43210$, USA

${ }^{2}$ Dept. of Mechanical Engineering and Materials Science, Institute of Materials Science and Engineering, Washington University, One Brookings Drive, St. Louis, MO, 63130, USA

Corresponding author: Anupam Vivek, email: vivek.4@osu.edu, 608-332-4892

\begin{abstract}
The objective of this study was to create impact welds between a Zr-based Bulk Metallic Glass (BMG) and copper at a laboratory scale and subsequently investigate the relationship between interfacial structure and mechanical properties. Vaporizing Foil Actuator (VFA) has recently been demonstrated as a versatile tool for metalworking applications: impact welding of dissimilar materials being one of them. Its implementation for welding is termed as VFA Welding or VFAW. With $8 \mathrm{~kJ}$ input energy into an aluminum foil actuator, a $0.5 \mathrm{~mm}$ thick Cu110 alloy sheet was launched toward a BMG target resulting in an impact at a velocity of nearly $600 \mathrm{~m} / \mathrm{s}$. For this experiment, the welded interface was straight with a few BMG fragments embedded in the copper sheet in some regions. Hardness tests across the interface showed increase in strength on the copper side. Instrumented peel test resulted in failure in the parent copper sheet. A slower impact velocity during a separate experiment resulted in a weld which had wavy regions along the interface and in peel failure again happened in the parent copper sheet. Some through-thickness cracks were observed in the BMG plate and there was some spall damage in the copper flyers. TEM electron diffraction on a sample, cut out from the wavy weld interface region using a focused ion beam, showed that devitrification of the BMG was completely avoided in this welding process.
\end{abstract}

KEYWORDS: Impact welding; Copper; Bulk metallic glass 


\section{Introduction}

Bulk metallic glasses (BMGs) are amorphous alloys which offer several advantages over traditional crystalline metals. High strength, low density, high elastic limit and good corrosion resistance make BMGs a desirable material for several applications [1]. However, due to limited or no plasticity in tension, BMGs have found limited structural applications. BMG matrix composites have been proposed as a viable solution to this shortcoming [2, 3]. Schroers and Johnson [4] have also reported on a ductile Platinum-based BMG, which showed plastic strains of up to $20 \%$. However, most BMGs are known to be materials with limited plasticity.

In order for BMGs to be more useful, their integration into multi-material structures is of importance. Liquid phase welding or brazing is not suitable as crystallization of the glassy components can occur upon solidification if the cooling rate is too low [5]. If the cooling rate is fast enough to prevent crystallization, as is the case in reactive foil joining [6], pulsed-current welding [7] or electron-beam welding [8], welding of BMGs with transient liquid state has been shown to be feasible. Solid-state welding techniques, such as friction-stir welding (FSW) [9], explosive welding (EXW) [10, 11], and magnetic pulse welding (MPW) [12] have been successful to some degree in solid-state welding of BMGs to BMGs or to other crystalline metals.

Vaporizing Foil Actuators (VFA) are based on the phenomenon of rapid vaporization of thin metallic foils and wires caused by passage of a capacitor bank driven current, on the order of $100 \mathrm{kA}$. The burst of the conductor is accompanied with a high-pressure pulse which, as in the case of VFA, can be used for working metal at high strain rates. VFA have been applied toward a variety of impulse-based metal working operations such as impact welding, embossing, shearing, dynamic powder consolidation, shape calibration, and sheet metal forming [13]. 
This paper focuses on applying VFA to weld a crystalline copper sheet to a zirconium-based bulk metallic glass. Copper-titanium, aluminum-copper, aluminum-magnesium, titanium-steel, copper-steel welds were also created by Vivek et al. [13]. Flyer sheet impact velocities up to 670 $\mathrm{m} / \mathrm{s}$ were measured. The weld interfaces were found to have significantly different structures and strengths. Some of the welds, such as copper-titanium, had high peel strengths, such that cohesive failure is forced into the weaker (copper) material in peel testing and these interfaces have typically a wavy structure, free of intermetallics and voids. However, a few others, like steel-titanium, were often found to be weak and riddled with interfacial defects unless optimized with interfacial layers or other methods.

Impact welding has been traditionally practiced using explosive driven pulses or less commonly by the electromagnetic launch of flyers [15]. Critical diameter, stringent handling and storage regulations, and inability to scale down the process are some issues due to which Explosive welding finds limited application in traditional industrial environments. The most significant drawback of MPW is the limited magnetic pressure that the actuators can operate at without their catastrophic failure [16]. Additionally, MPW works efficiently only for combinations where the flyer sheet is electrically conductive. VFAW can be used to create welds of the length scales similar or greater to than those of MPW, and can accelerate flyers to velocities similar to those during EXW. The issue of actuator longevity does not exist as the foil actuator, which is disposable, can be easily replaced after every experiment at a low cost. Together these advantages allow VFAW to join both high and low strength materials that are generally on the order of a millimeter thick with bond lengths on the order of centimeters.

A set up very similar to the one used by the authors in previous work was used here to weld a $3 \mathrm{~mm}$ thick BMG plate with $0.5 \mathrm{~mm}$ thick copper sheet. Another experiment, with a $0.5 \mathrm{~mm}$ thick titanium sheet and $0.25 \mathrm{~mm}$ thick copper interlayer, was also implemented. The welded 
samples were subjected to peel tests, optical microscopy, and microhardness tests. TEM electron diffraction of a foil cut out from the BMG-Cu weld interface was also implemented to check for any evidence of crystallization of the BMG. The experimental procedure and results are presented in subsequent sections.

\section{Materials and Methods}

For this investigation, $25 \mathrm{~mm} \times 55 \mathrm{~mm}$ rectangular strips cut out from $3 \mathrm{~mm}$ thick BMG cast plates with composition $\mathrm{Zr}_{58.5} \mathrm{Cu}_{15.6} \mathrm{Ni}_{12.8} \mathrm{Al}_{10.3} \mathrm{Nb}_{2.8}$ (Vit106a), were used. The average hardness of the BMG was $456 \mathrm{HV}$ while that of Cu 110 sheets was $95 \mathrm{HV}$. A schematic of the VFAW set up is shown in Figure 1. Aluminum foil actuators of thickness $0.0762 \mathrm{~mm}$ and shape as shown in Figure 1 (a) were placed underneath the flyer sheets which were stood off from the BMG target plates at a standoff distance (typically $2-3 \mathrm{~mm}$, as detailed later). The nominal welded length between the standoffs was $30 \mathrm{~mm}$. The standoffs were inserted to provide sufficient distance for acceleration of the flyer plates. Passage of a capacitor bank-driven current, on the order of $100 \mathrm{kA}$, through the foil actuator caused its rapid vaporization, thereby leading to a high pressure pulse which was used for launching the flyer sheet at high speed toward the target. The thick steel backing block ensured that the expanding plasma, formed from foil actuator's burst, did most of the mechanical work on the flyer sheet. A hole drilled through the backing blocks and the gap between BMG target plates provided a line of sight for a focuser probe of the Photonic Doppler Velocimeter (PDV) [17]. The PDV system used in this work [18] is capable of measuring velocities up to $1550 \mathrm{~m} / \mathrm{s}$ for a period of $2 \mathrm{~ms}$ with nanosecond time resolution.

The energy source used in these experiments was a Maxwell Magneform capacitor bank with a total capacitance of $426 \mu \mathrm{F}$, inductance of $100 \mathrm{nH}$, and short circuit current rise time of $12 \mu \mathrm{s}$. When charged to the maximum voltage of $8.6 \mathrm{kV}$, this capacitor bank can supply $16 \mathrm{~kJ}$ of electrical energy. As shown in Figure $1(\mathrm{e}, \mathrm{f}, \mathrm{g})$, three experiments with slightly different stacking 


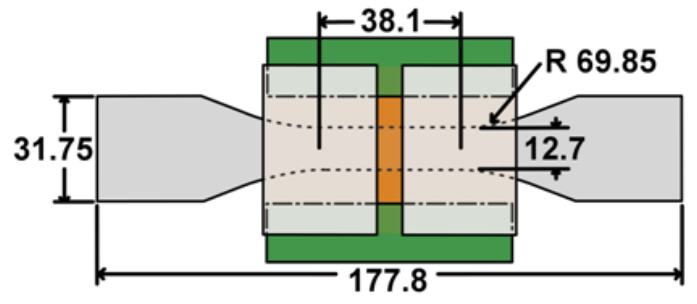

(a)

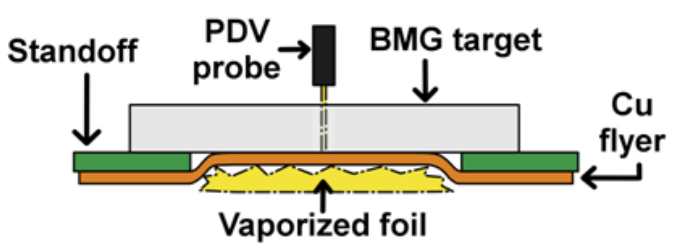

(c)

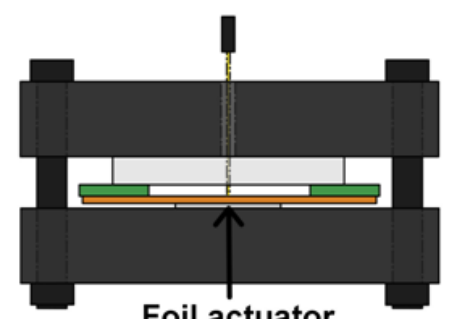

Foil actuator

(b)

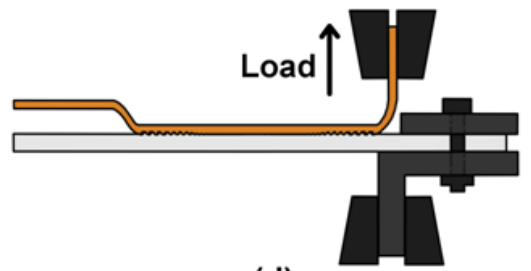

(d)

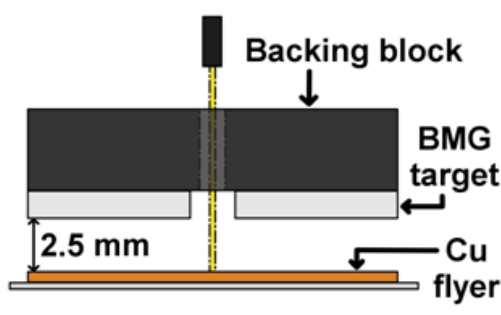

(e)

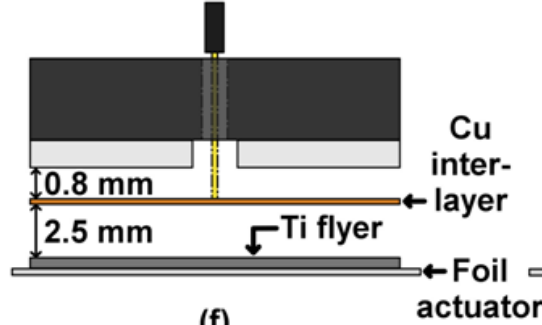

(f)

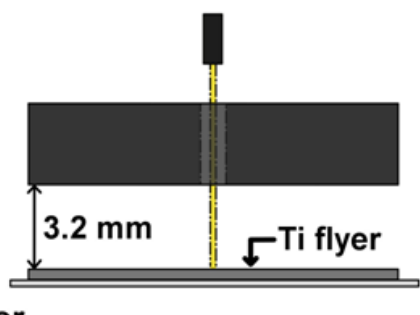

(g)

Figure 1 (2-column): Vaporizing foil actuator welding (VFAW) set up for welding Cu110 with BMG. (a) top view of the foil actuator, flyer sheet, standoff, and target stack, (b) side view of the stack along with the positioning of the Photonic Doppler Velocimeter (PDV) probe, (c) formation of weld after foil actuator's vaporization, (d) peel testing set up, $(e, f, g)$ different experimental configurations for welding and velocity measurement.

of the flyer and target sheets were conducted. In the first experiment, a $0.5 \mathrm{~mm}$ thick Cu110 sheet was vertically separated from the target plate by a distance of $2.5 \mathrm{~mm}$. The second experiment had a $0.5 \mathrm{~mm}$ thick commercially pure titanium sheet launched into a $0.25 \mathrm{~mm}$ thick Cu110 sheet which was in turn separated from the target BMG plate. The velocity of the free surface of the copper sheet was measured in this case. The third experiment was done for estimating the velocity with which the titanium sheet impacted the copper interlayer sheet. In 
this experiment, the PDV laser beam was focused over the titanium sheet by passing through holes and gaps in the layers above the titanium sheet. BMG plates were not used for this shot as the intent of this experiment was only velocity measurement. Input energy of $8 \mathrm{~kJ}$ was used in all the experiments. The welded samples were sectioned using a circular abrasive saw and either mounted for optical microscopy and hardness testing, or subjected to peel testing. TEM foils were extracted using a FEI Nova DualBeam ${ }^{\mathrm{TM}}$ and attached to a copper grid, then thinned to electron transparency using 30 and $5 \mathrm{kV}$ gallium ions. In both types of welds, Cu-BMG or TiCu-BMG, the microscopy work was focused on the Cu-BMG interface.

In the welded samples, the flyer and interlayer sheets were bent to $90^{\circ}$ with respect to the target plate and the samples were pulled apart using a MTS 831.10 load frame at a displacement rate of $0.1 \mathrm{~mm} / \mathrm{sec}$. Force displacement curves were obtained for all the samples. The load bearing capacity of the weld was normalized by dividing the sustained load by the width of the sample being peeled. Microhardness testing was done across the BMG-Cu interfaces. A diamond indenter with $200 \mathrm{~g}$ load was used for the BMG side while a $50 \mathrm{~g}$ load was used for the copper side.

\section{Results and discussion}

A typical current, voltage and velocity trace is shown in Figure 2. Before the foil burst, there is a period over which the flyer undergoes low acceleration due to its electromagnetic interaction with the current carrying foil. The foil burst corresponds with the local maxima depicted in the voltage curve. This spike in voltage is a common phenomenon and can be explained on the basis of sudden rise in the resistance of the foil when it vaporizes and converts into plasma at high pressure. Subsequent expansion of plasma reduces the pressure and once the remaining voltage equals the breakdown voltage of the vapor, it starts conducting again [19]. 


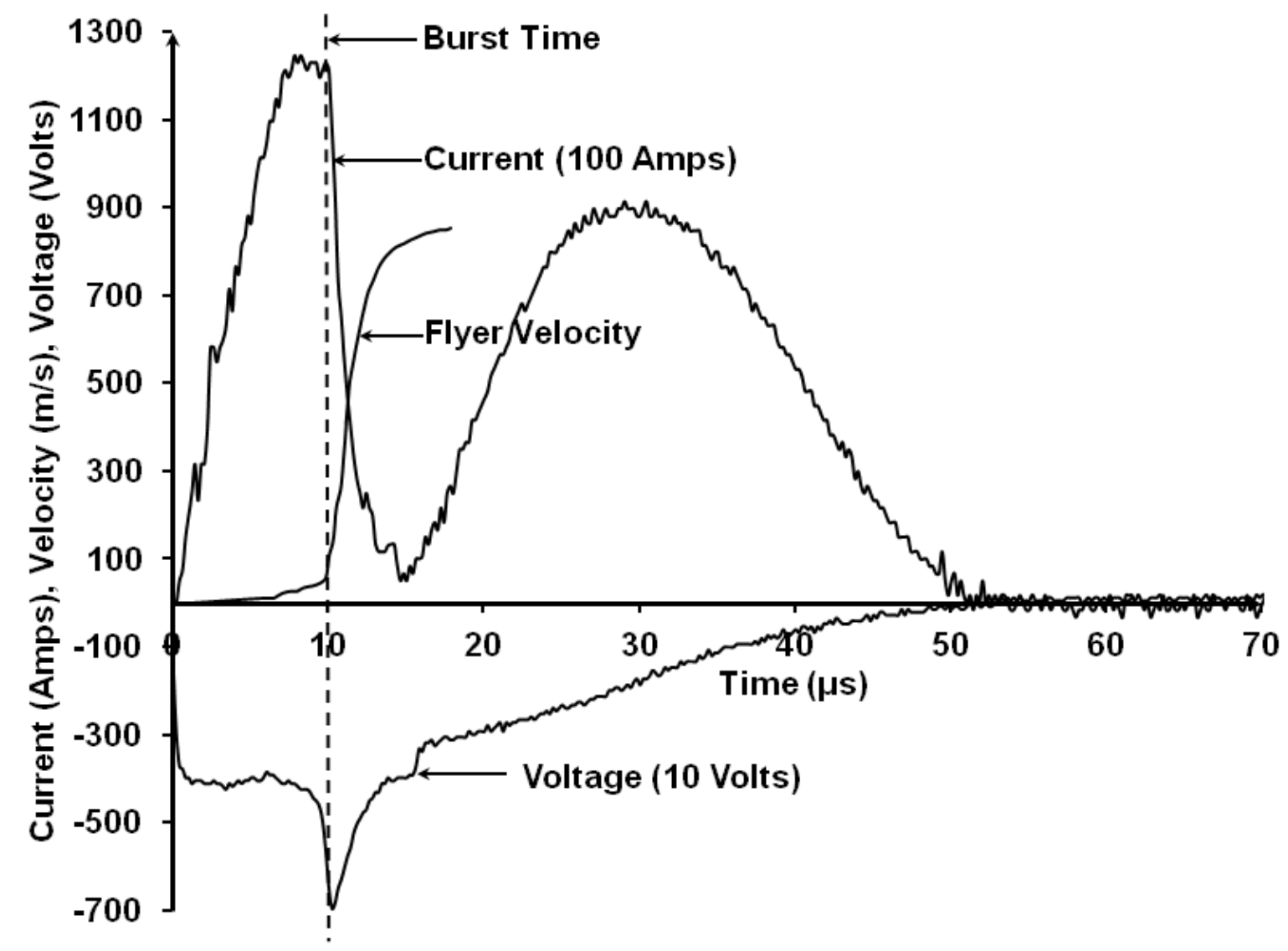

Figure 2 (1-column): A typical current, voltage, and velocity data generated from a VFAW experiment

The evolution of flyer velocities over time is shown in Figure 3. An $8 \mathrm{~kJ}$ launch of the $0.5 \mathrm{~mm}$ thick copper sheet resulted in an impact velocity of nearly $600 \mathrm{~m} / \mathrm{s}$. The titanium flyer impacted the copper interlayer at approximately $800 \mathrm{~m} / \mathrm{s}$ and the free surface of the $0.25 \mathrm{~mm}$ thick copper interlayer was launched to $500 \mathrm{~m} / \mathrm{s}$. The copper interlayer, which was partially welded to the titanium flyer and travelled with it, decelerated slightly and impacted the BMG plate at nearly $460 \mathrm{~m} / \mathrm{s}$. As the flyers collapsed on to the BMG plates the impact angle increased. 


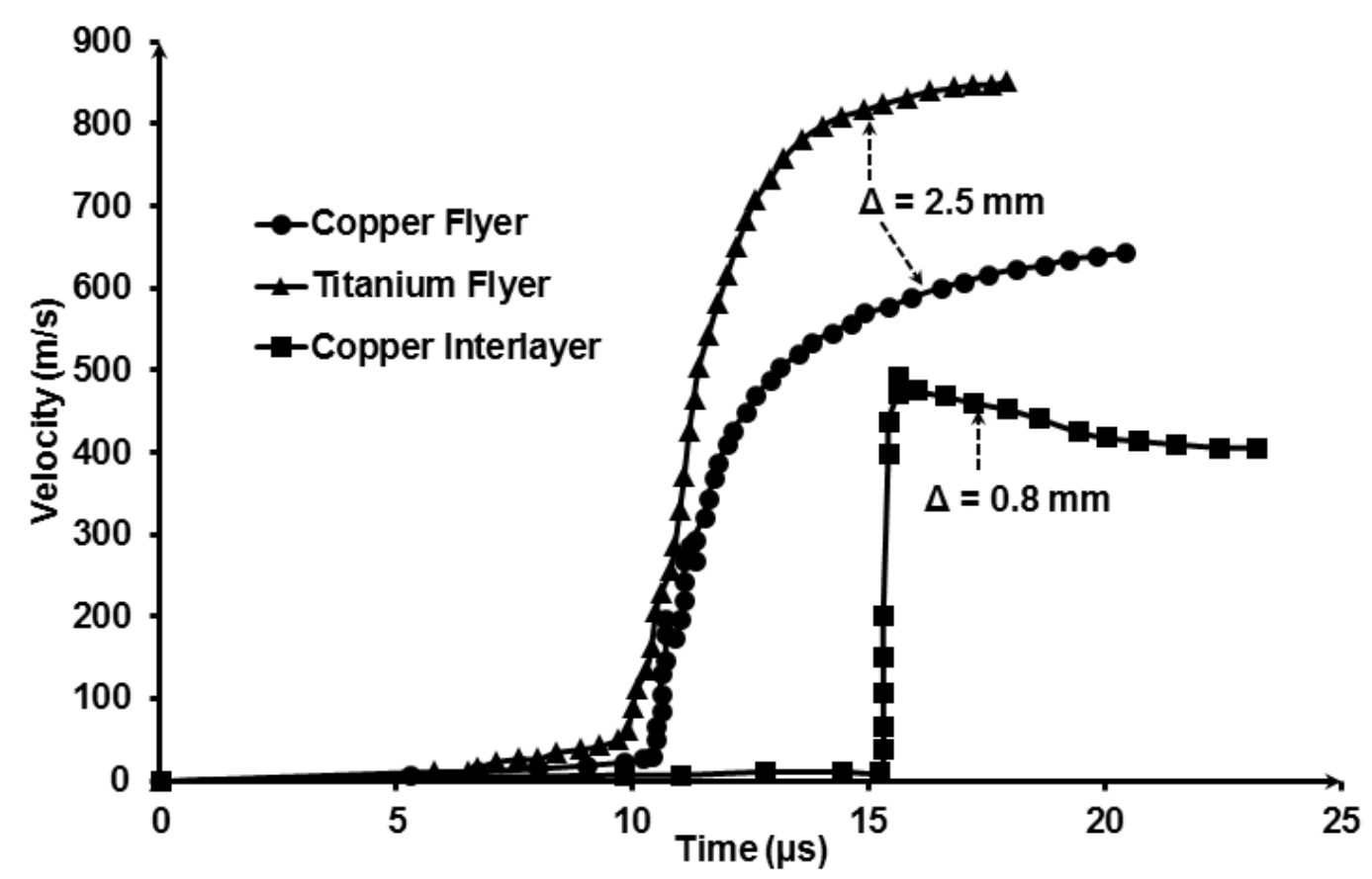

Figure 3 (1-column): Temporal evolution of the velocities of different flyers with $8 \mathrm{~kJ}$ input energy into a $0.0762 \mathrm{~mm}$ thick foil actuator. The impact velocities are pointed out by dotted arrows. The copper flyer impacted the BMG plate after travelling $2.5 \mathrm{~mm}$ while the titanium flyer travelled the same distance before impacting the copper interlayer. The copper interlayer impacted the BMG target plate after travelling 0.8 $m m$.

The cross section of the Cu-BMG welded sample is shown in Figure 4. The three-body (Ti-CuBMG) had similar appearance and is not shown. Because the region of the copper flyer directly above the foil actuator remains horizontal after the launch, the angle of impact in that area is zero degree and no welding occurs. As the rest of the flyer collapses onto the target, welding occurs in the region where the angle and velocity of impact are within the impact welding window [20, 21]. The flyer is raised from the target at the former position of the standoffs, which were removed after the experiment. 


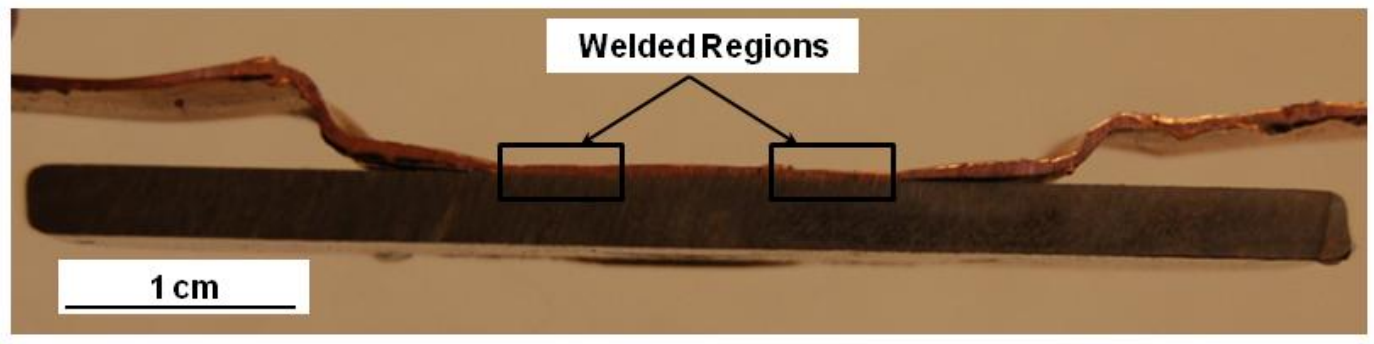

Figure 4 (1-column): Cross section of the Cu-BMG weld sample.

Without exploring the effects of impact angles and speed in detail, it can be seen from Figure 5 that the two experiments yielded distinct types of welded interfaces. It should also be noted that since the experiments were not repeated, the observations made here may not be representative of the relationship between structure and input parameters. As evident from Figure 5, even in a single experiment, the interface morphology varies at different regions of the weld because the impact parameters evolve as the flyer sheet collapses on to the target plate. For the two-body experiment shown in Figure 5a, Cu-BMG welding occurred at an initial impact velocity of nearly $600 \mathrm{~m} / \mathrm{s}$. The interface was mostly flat and in some regions there were multiple BMG fragments embedded in the copper side. These fragments were possibly formed during the jetting process, which is necessary for impact welding, and projected into the copper flyer rather than escaping from between the two colliding surfaces. Due to their irregular shape, these fragments were often accompanied by micro-voids. For the three-body experiment shown in Figure 5b, the Cu-BMG weld was created at a lower velocity of $460 \mathrm{~m} / \mathrm{s}$ and had a distinct region of wavy interface which is characteristic of an impact weld created under conditions within the welding window. There are several theories propounded to explain the phenomenon of a wavy interface in impact welds [22]. All those theories rely on the fact that metals coming in contact at very high pressure act as fluids. The flow of these fluids becomes turbulent beyond a certain relative velocity, and waves are formed at the interface [23]. The stress waves reflected from the free surfaces of the target and flyer plates also cause perturbations, which manifest as 
waves at the interface [24]. If the welding velocity is more than the sonic speed in the materials, then the interfacial waves get suppressed [21]. This could be the reason for a flat interface in the two-body experiment, which had an impact velocity of $600 \mathrm{~m} / \mathrm{s}$.

In both experiments, some cracks were observed in the BMG target, but they did not go through the thickness. Rigid support on all sides of the BMG strip can help further reduce such damage. Some damage to the copper interlayer in the form of incipient spalling was observed near the interface. In application, higher impact angle and lower impact velocity in those regions will help avoid such damage mechanisms.

(a)

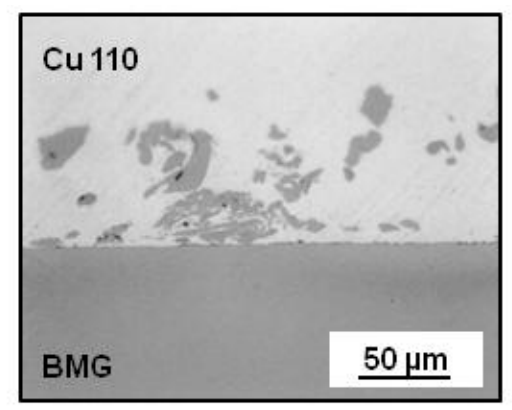

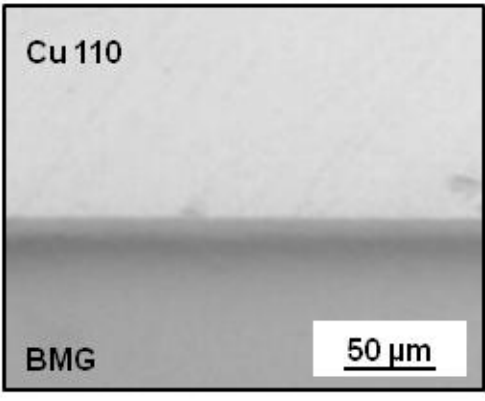

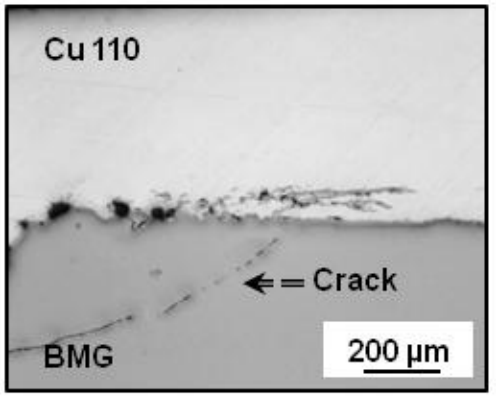

(b)
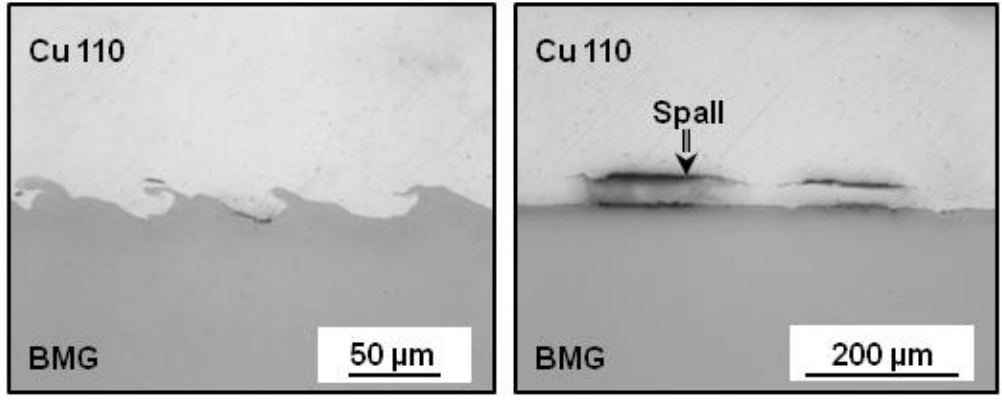

Figure 5 (2-column): Morphology of the Cu-BMG weld interface and welding induced defects in (a) Different regions of the Cu-BMG weld occurring at high impact velocity ( $600 \mathrm{~m} / \mathrm{s})$, (b) Different regions of Ti-Cu-BMG weld occurring at a lower impact velocity ( 460 m/s). A wavy interface occurred for lower impact velocity. 
Microhardness traverses across the interfaces, plotted in Figure 6, showed that the hardness of the copper sheets was higher than the parent material. For the flat interface shown in Figure 5(a), the hardness increase in copper was most significant which indicated high magnitude of shock induced hardening or plastic work. The refinement of the copper grains near the interface due to shock hardening and extensive plastic work is also expected to be a dominant mechanism for hardening. The as-received copper had an average grain size of $10 \mu \mathrm{m}$, whereas, the grain size of the copper near the interface was found to be less than $500 \mathrm{~nm}$. Sun et al. [9] reported that the hardness of copper actually decreased around the weld interface during friction stir welding because the effect of strain hardening and grain refinement was overcome by annealing due to the high amount of heat generated from plastic work. No such trend was observed in the present work because the VFAW process was fast enough to prevent annealing effects. In each type of interface, there was a slight decrease in the hardness of BMG nearly $100 \mu \mathrm{m}$ away from the interface. Further microscopic analysis needs to be done to understand the mechanisms for changes in microhardness on either side of the weld interface.

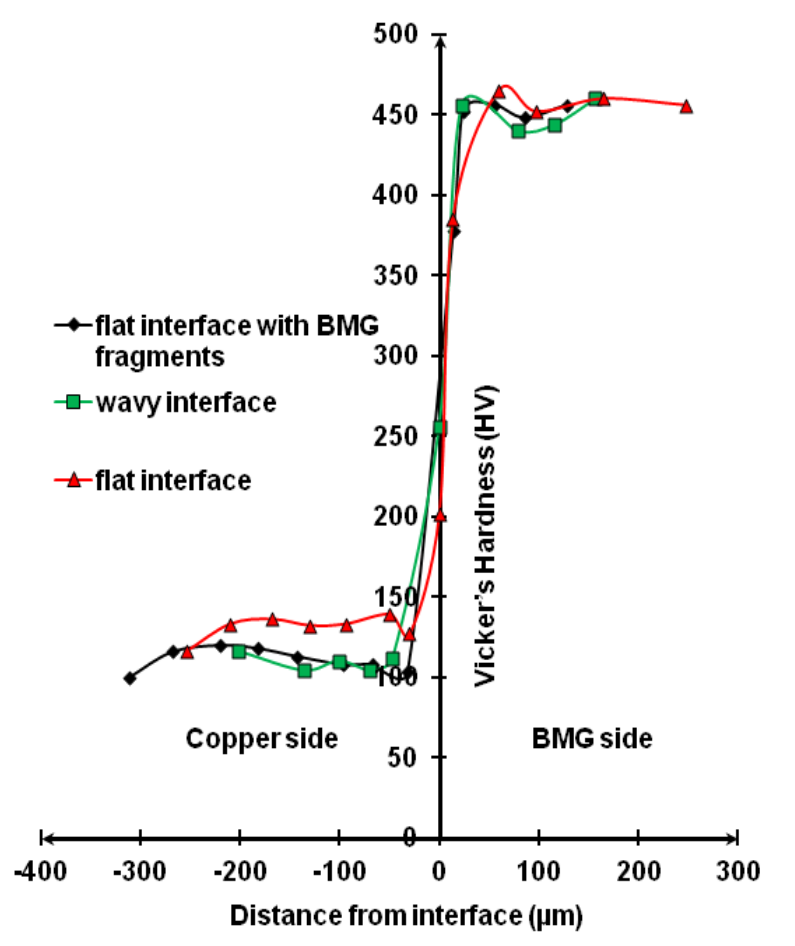

Figure 6 (1-column): Variation of microhardness across the different types of interfaces. 
The heat affected zone and dwell time of the FSW process reported by Sun et al. [9] was much higher than that of VFAW. Since they did not observe any evidence of crystallization of BMG, it can be expected that it would not to happen with VFAW either. To verify this hypothesis, TEM diffraction analysis was done. A $100 \mathrm{~nm}$ thick foil, shown in Figure 7, was extracted from the wavy weld interface between the $\mathrm{Cu}$ interlayer and BMG using a focused ion beam. A clear difference in sputtering behavior between the copper and BMG can be seen in the trench before undercutting. A bright field image of the foil is shown in Figure 8 along with selected area diffraction (SAD) patterns observed for different regions across the interface. Three areas were chosen: (a) completely in the copper, (b) partially in copper and BMG, (c) completely in BMG. The SAD patterns for areas "b" and "c" show strong amorphous rings with no speckling indicating purely amorphous material. The diffraction spots corresponding to copper regions disappeared as the SAD aperture was moved into the BMG region. Given this and the clearly amorphous pattern from the BMG region seen in area "c" it shows that crystallization of the BMG was completely avoided near the weld interface.

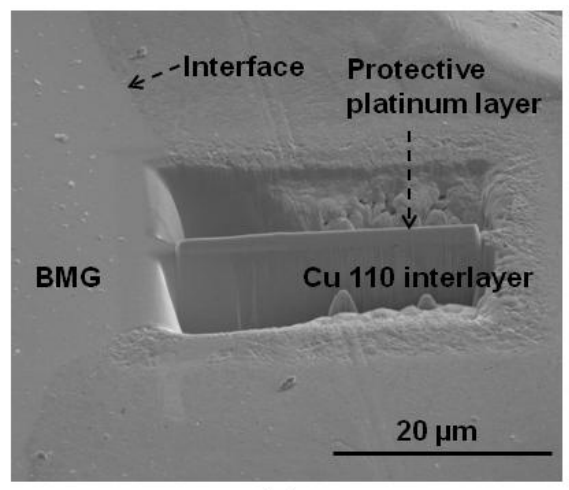

(a)

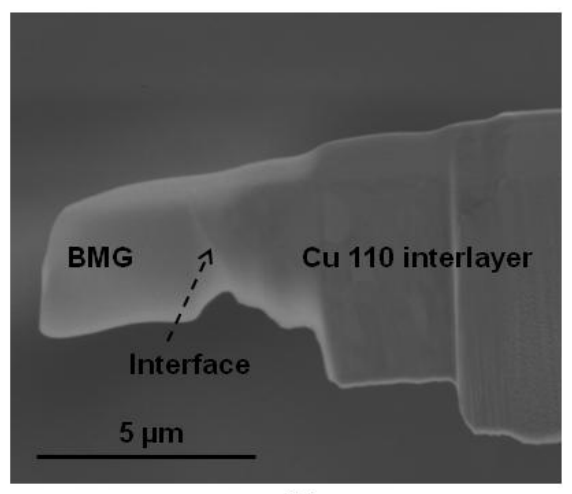

(b)

Figure 7 (1.5-column): (a) Focused ion beam milling of foil from the copper-BMG weld interface, (b) electron-transparent foil to be subjected to TEM. 


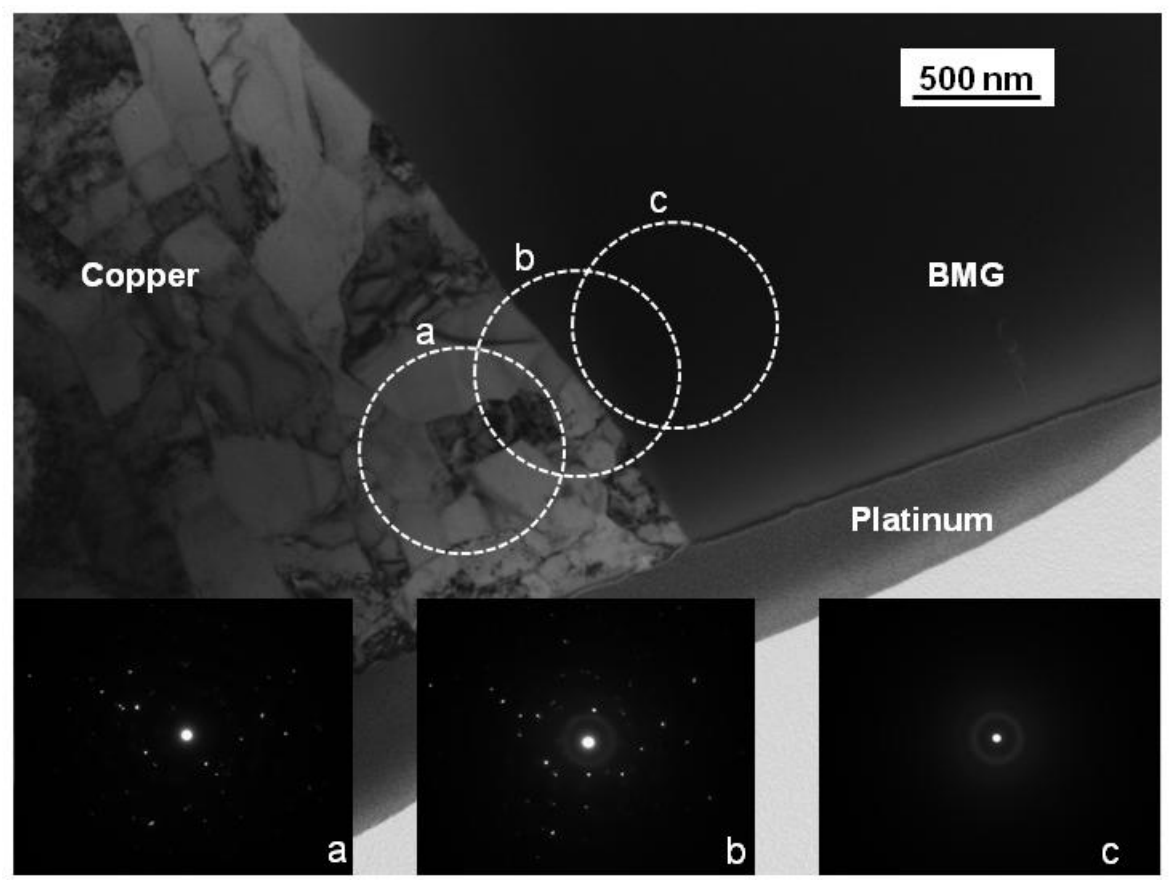

Figure 8 (1.5-column): Bright field image of the Cu-BMG weld interface and selected area diffraction patterns of different regions: (a) completely in the copper, (b) partially in copper and BMG, (c) completely in BMG.

The data from the peel test of both types of samples is shown in Figure 9. The tested samples are shown to depict the region of failure during testing. While peeling the titanium flyer from the Ti-Cu-BMG weld, failure took place along the Ti-Cu interface. This was not surprising, as even before peeling of the three-body sample, some delamination had already occurred in the Ti-Cu interface due to rebound during the progress of the welding process. For the same sample, when the copper interlayer was pulled, failure happened in the copper and the Cu-BMG interface remained intact. Similarly, when the Cu-BMG weld was peel tested, failure occurred in the copper. This proved that the Cu-BMG bond was quite strong in both cases. Based on the obtained data, the peel strength of the Cu-BMG bond is in excess of $70 \mathrm{~N} / \mathrm{mm}$. The peel strength of the Ti-Cu weld was approximately $15 \mathrm{~N} / \mathrm{mm}$ which can be increased if the conditions were to be optimized for that particular weld, as has been shown in prior studies [21] 


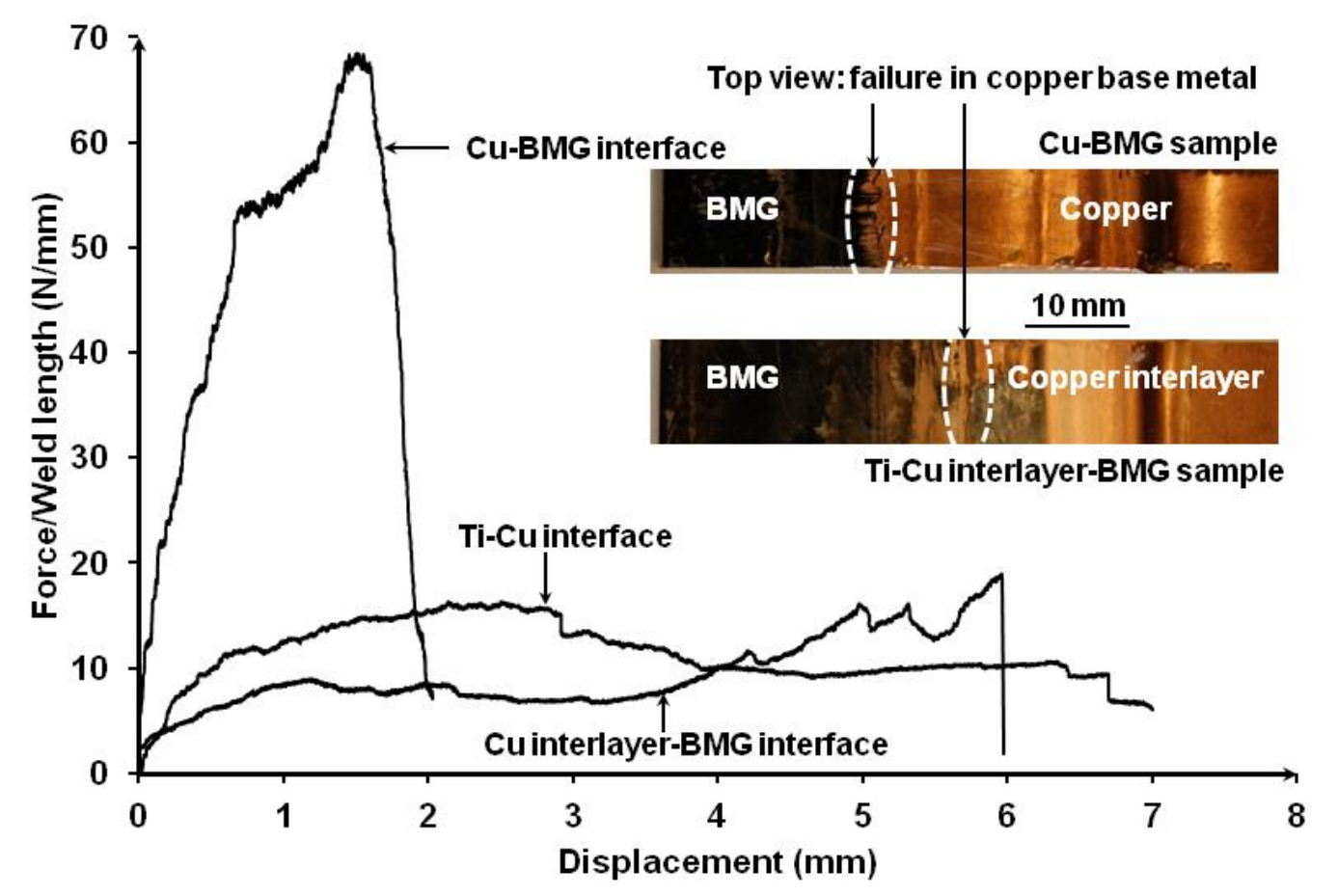

Figure 9 (1.5-column): Peel testing of the two samples resulting in failure in the parent copper flyer and interlayer. The top views of the peeled samples are inset in the figure.

\section{Conclusions and future outlook}

Based on this work on welding of BMG, the following conclusions can be made:

- VFAW was demonstrated to be a feasible method to weld BMG with copper and the joint was found to be stronger than the weaker of the parent materials, since during peel testing failure occurred in copper sheets.

- Depending on the impact parameters and boundary conditions, different weld interface morphologies can be created. A wavy interface was formed at a low impact velocity of $460 \mathrm{~m} / \mathrm{s}$, whereas, smooth regions were obtained for a higher initial impact velocity of nearly $600 \mathrm{~m} / \mathrm{s}$. There was also a case in which BMG fragments were found to be dispersed in the copper near the interface.

- Hardness of the copper sheets increased after the impact welding process, probably due to grain refinement due to shock hardening and extensive strain hardening. 
- Crystallization of the BMG was avoided during the welding process.

The results of this work open a new avenue for welding BMG. Further research concerning weld formation mechanisms and exploration of the possibility of welding other materials with BMG using VFAW can be done in a laboratory setting. These tests represent a simple exploration of feasibility. Further work is required to optimize welding parameters to create high quality welds between both bodies in a 3-layer structure, while between this study and prior work [25] high strength bonds have been demonstrated both between copper and BMG, and copper and titanium.

\section{Acknowledgement}

AV and GSD are grateful for sponsorship from the U.S. Department of Energy's Vehicle Technologies Office under grant number DE-EE0006451, as well as the ALCOA Foundation's Advancing Sustainability Research Initiative. NHH and KMF acknowledge support from the Air Force Office of Scientific Research under Grant No. FA9550-12-1-0059. Contributions from research group members, Steve Hansen, Bert Liu, Jason Johnson, and Geoff Taber with respect to establishing experimental procedures are also deeply appreciated.

\section{References}

1. Wang, Wei-Hua, Chuang Dong, and C. H. Shek. (2004), "Bulk metallic glasses."Materials Science and Engineering: R: Reports 44, no. 2: 45-89.

2. Choi-Yim, H., \& Johnson, W. L. (1997). Bulk metallic glass matrix composites. Applied physics letters, 71(26), 3808-3810.

3. Hofmann, Douglas C., Jin-Yoo Suh, Aaron Wiest, Gang Duan, Mary-Laura Lind, Marios D. Demetriou, and William L. Johnson. "Designing metallic glass matrix composites with high toughness and tensile ductility." Nature 451, no. 7182 (2008): 1085-1089. 
4. Schroers, Jan, and William L. Johnson. "Ductile bulk metallic glass." Physical Review Letters 93, no. 25 (2004): 255506.

5. Johnson, W. L. "Bulk amorphous metal—An emerging engineering material."Jom 54, no. 3 (2002): 40-43.

6. Swiston Jr, A. J., E. Besnoin, A. Duckham, O. M. Knio, T. P. Weihs, and T. C. Hufnagel. "Thermal and microstructural effects of welding metallic glasses by self-propagating reactions in multilayer foils." Acta materialia 53, no. 13 (2005): 3713-3719.

7. Kawamura, Y. "Liquid phase and supercooled liquid phase welding of bulk metallic glasses." Materials Science and Engineering: A 375 (2004): 112-119.

8. Kagao, S., Kawamura, Y., \& Ohno, Y. (2004). Electron-beam welding of Zr-based bulk metallic glasses. Materials Science and Engineering: $A$, 375, 312-316.

9. Sun, Y., Ji, Y., Fujii, H., Nakata, K., \& Nogi, K. (2010). Microstructure and mechanical properties of friction stir welded joint of Zr55Cu30Al10Ni5 bulk metallic glass with pure copper. Materials Science \& Engineering A, 527(15), 3427.

10. Chiba, A., Kawamura, Y., \& Nishida, M. (2008, February). Explosive welding of ZrTiCuNiBe bulk metallic glass to crystalline metallic plates. In Materials Science Forum (Vol. 566, pp. 119-124).

11. Liu, W. D., Liu, K. X., Chen, Q. Y., Wang, J. T., Yan, H. H., \& Li, X. J. (2009). Metallic glass coating on metals plate by adjusted explosive welding technique. Applied Surface Science, 255(23), 9343-9347.

12. Hutchinson, Nicholas W. "Experimental input for the design of metallic glass/crystalline composites." PhD diss., The Ohio State University, 2013.

13. Vivek, A., Daehn, G. S. (2014). Vaporizing Foil Actuator: A Versatile Tool for High Energy-rate Metal Working. Procedia Engineering, 81, 2129-2134. 
14. Vivek, A., S. R. Hansen, B. C. Liu, and Glenn S. Daehn. "Vaporizing Foil Actuator: A Tool for Collision Welding." Journal of Materials Processing Technology (2013). 213-12, pp 2304-2311.

15. Psyk, V., D. Risch, B. L. Kinsey, A. E. Tekkaya, and M. Kleiner. "Electromagnetic forming_A review." Journal of Materials Processing Technology 211, no. 5 (2011): 787829.

16. Golovashchenko, Sergey F. "Material formability and coil design in electromagnetic forming." Journal of Materials Engineering and Performance 16, no. 3 (2007): 314-320.

17. Strand, O. T., Goosman, D. R., Martinez, C., Whitworth, T. L., \& Kuhlow, W. W. (2006). Compact system for high-speed velocimetry using heterodyne techniques. Review of Scientific Instruments, 77(8), 083108.

18. Vivek, A., Hansen, S. R., \& Daehn, G. S. (2014). High strain rate metalworking with vaporizing foil actuator: Control of flyer velocity by varying input energy and foil thickness. Review of Scientific Instruments, 85(7), 075101.

19. Webb, F. H., Chase, N., Ernstene, M., and Tollestrup A. V., (1959), "Submicrosecond Wire Explosion Studies at Electro-Optical Systems, Inc."Exploding Wires 1: 33.

20. Akbari Mousavi, S. A. A., \& Farhadi Sartangi, P. (2009). Experimental investigation of explosive welding of cp-titanium/AISI 304 stainless steel. Materials \& Design, 30(3), 459468.

21. Deribas, A. A., Simonov, V. A., \& Zakcharenko, I. D. (1975). Investigation of explosive welding parameters for arbitrary combinations of metals and alloys. In Proc. 5th Int. Conf. on High Energy Rate Fabrication (Vol. 4, pp. 1-4).

22. Crossland, B. (1982). Explosive Welding of Metals and Its Application. Clarendon Press, Oxford. 
23. Cowan, G. R., Bergmann, O. R., \& Holtzman, A. H. (1971). Mechanism of bond zone wave formation in explosion-clad metals. Metallurgical and Materials Transactions $B, 2(11), 3145-3155$.

24. Hunt, J. N. (1968). Wave formation in explosive welding. Philosophical magazine, 17(148), 669-680.

25. Vivek, A., Liu, B. C., Hansen, S. R., \& Daehn, G. S. (2014). Accessing collision welding process window for titanium/copper welds with vaporizing foil actuators and grooved targets. Journal of Materials Processing Technology,214(8), 1583-1589. 


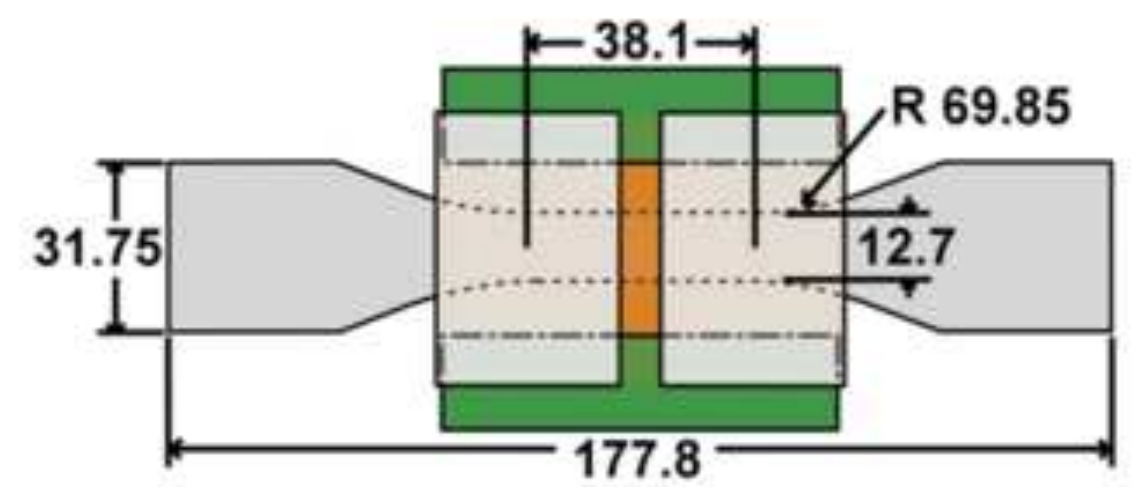

(a)

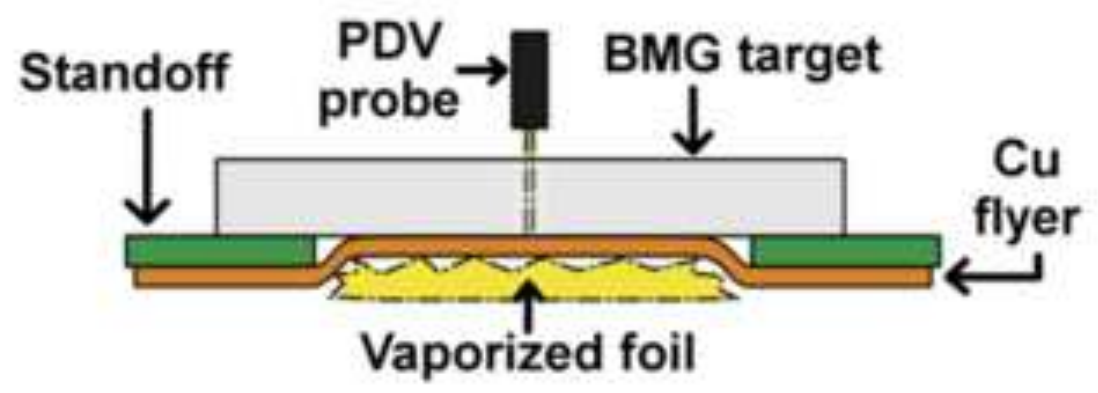

(c)

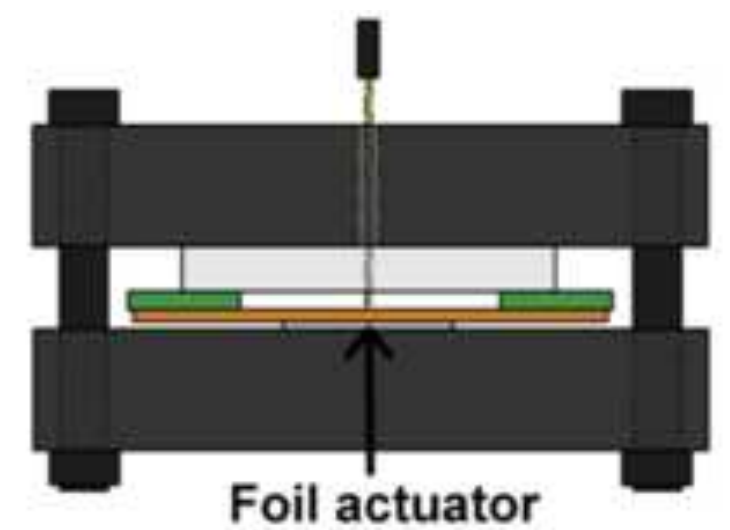

(b)

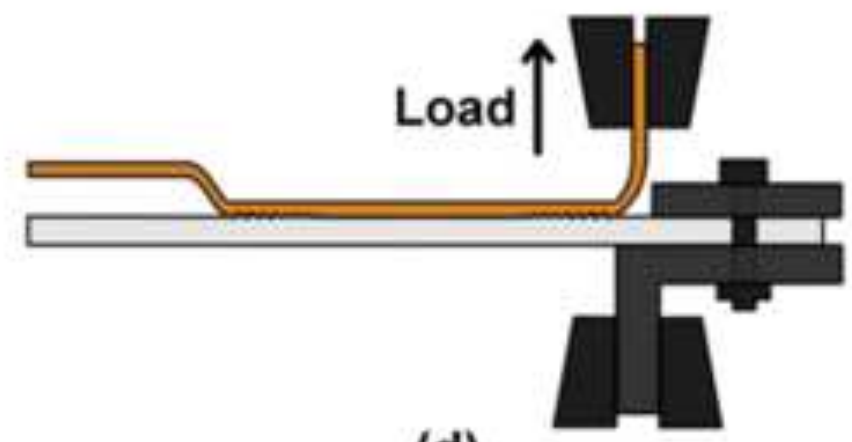

(d)

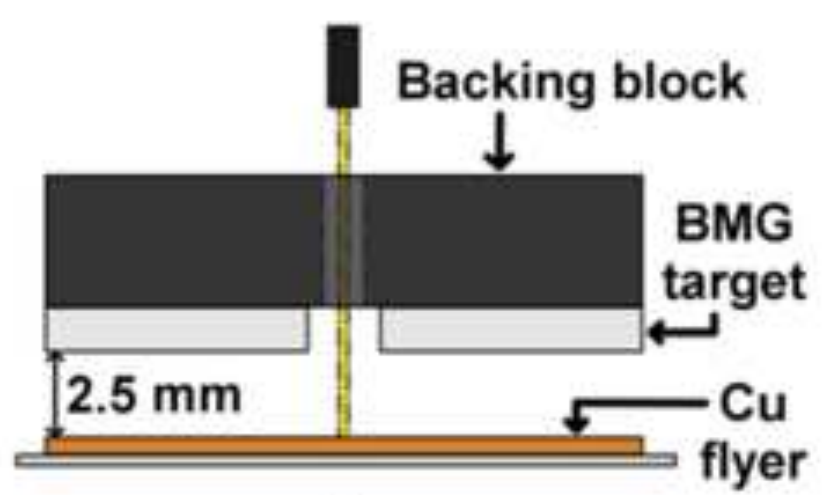

(e)
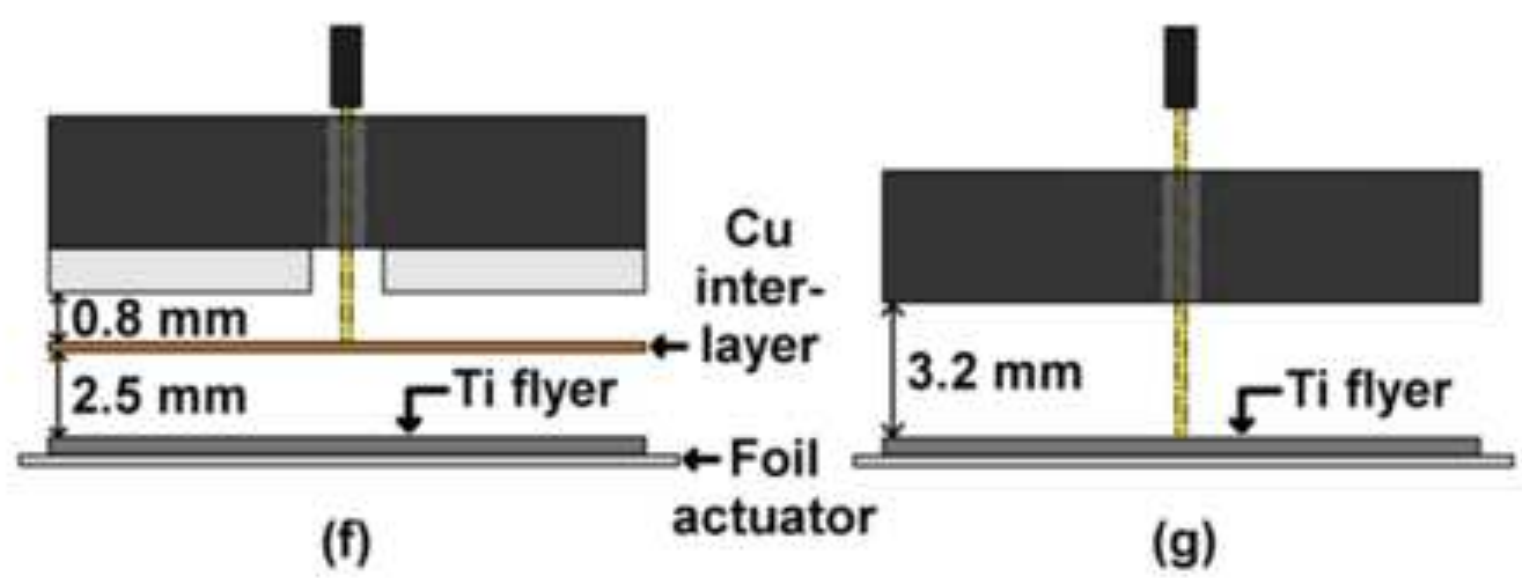

(g) 


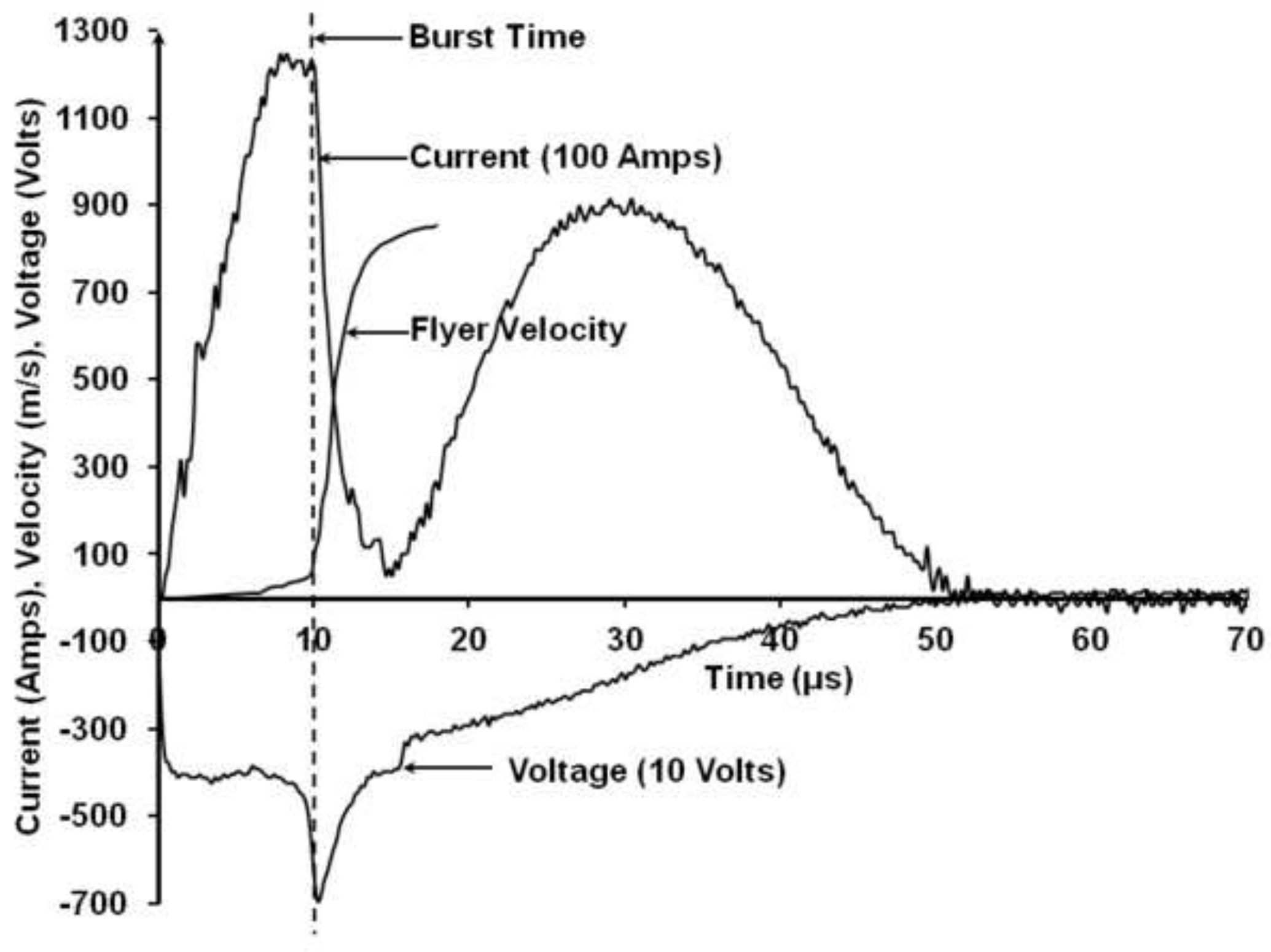




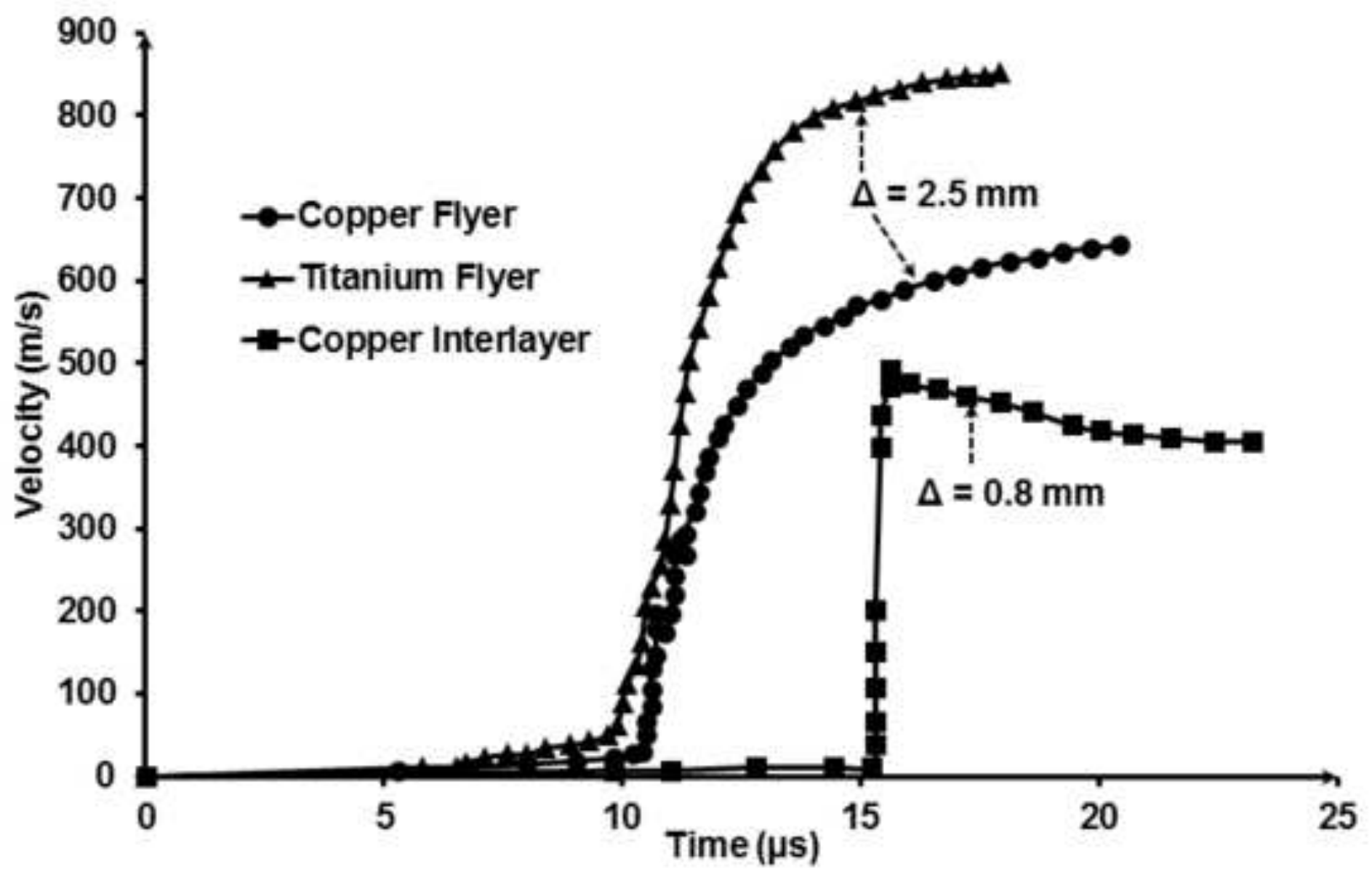




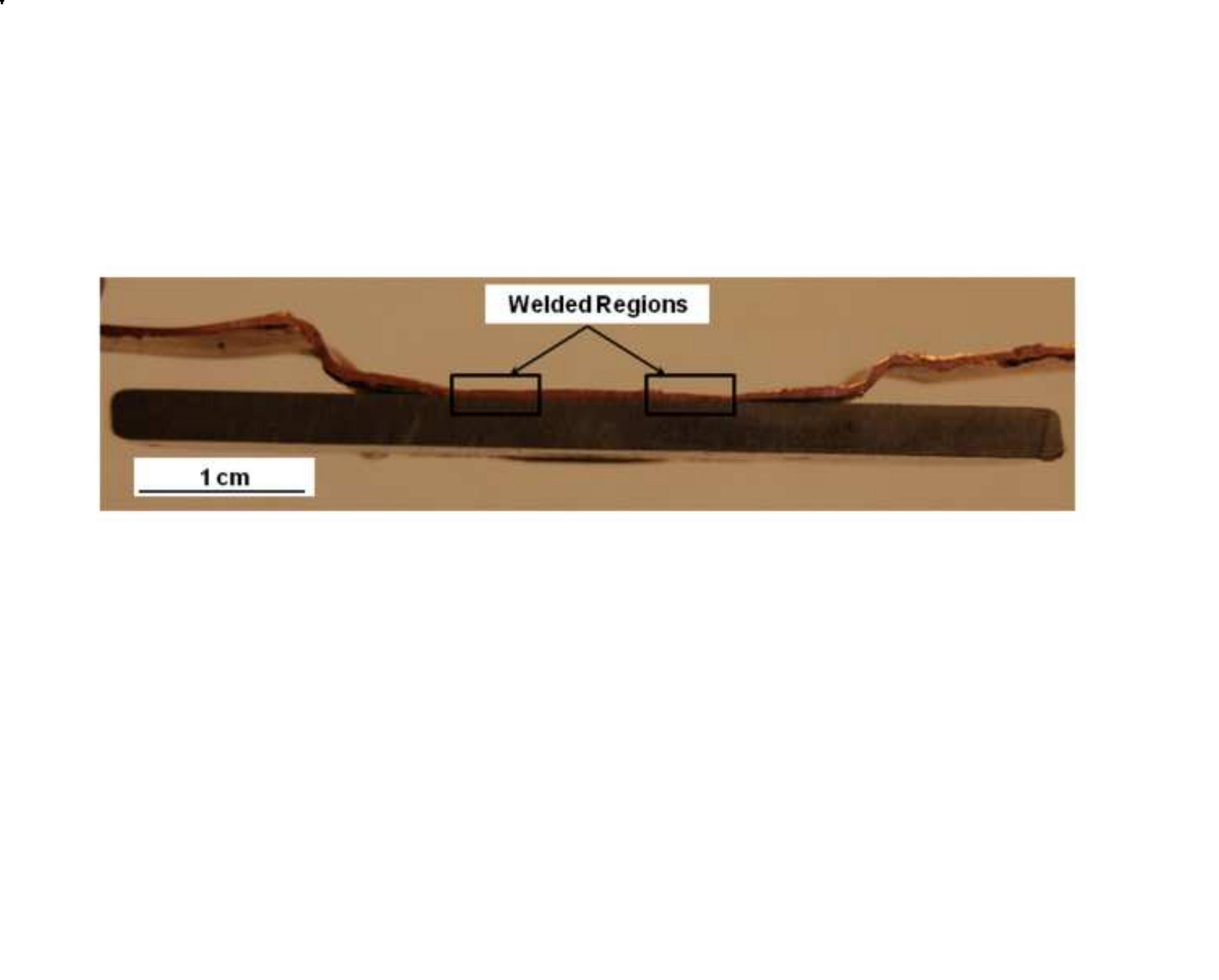

\section{$1 \mathrm{~cm}$}
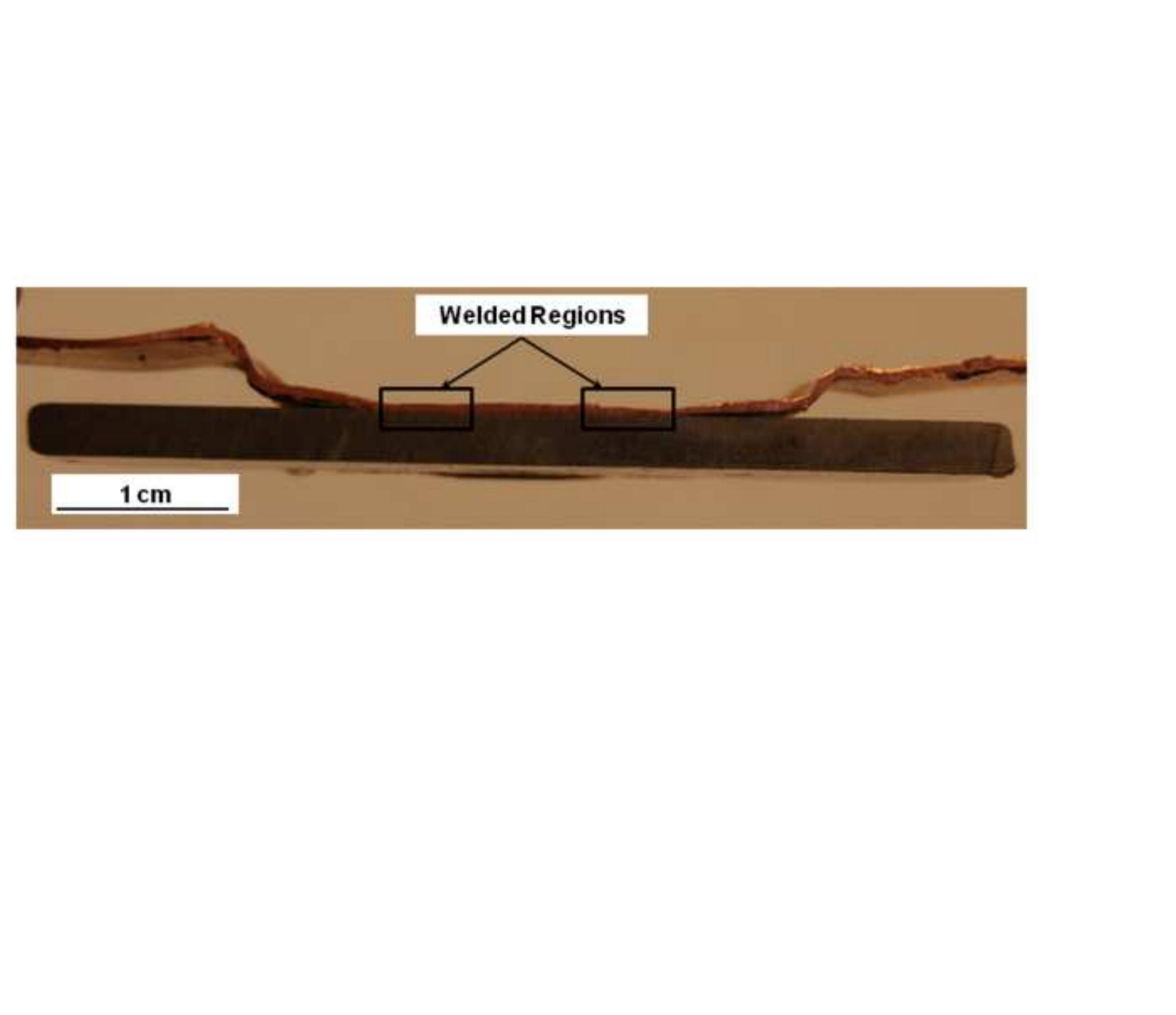


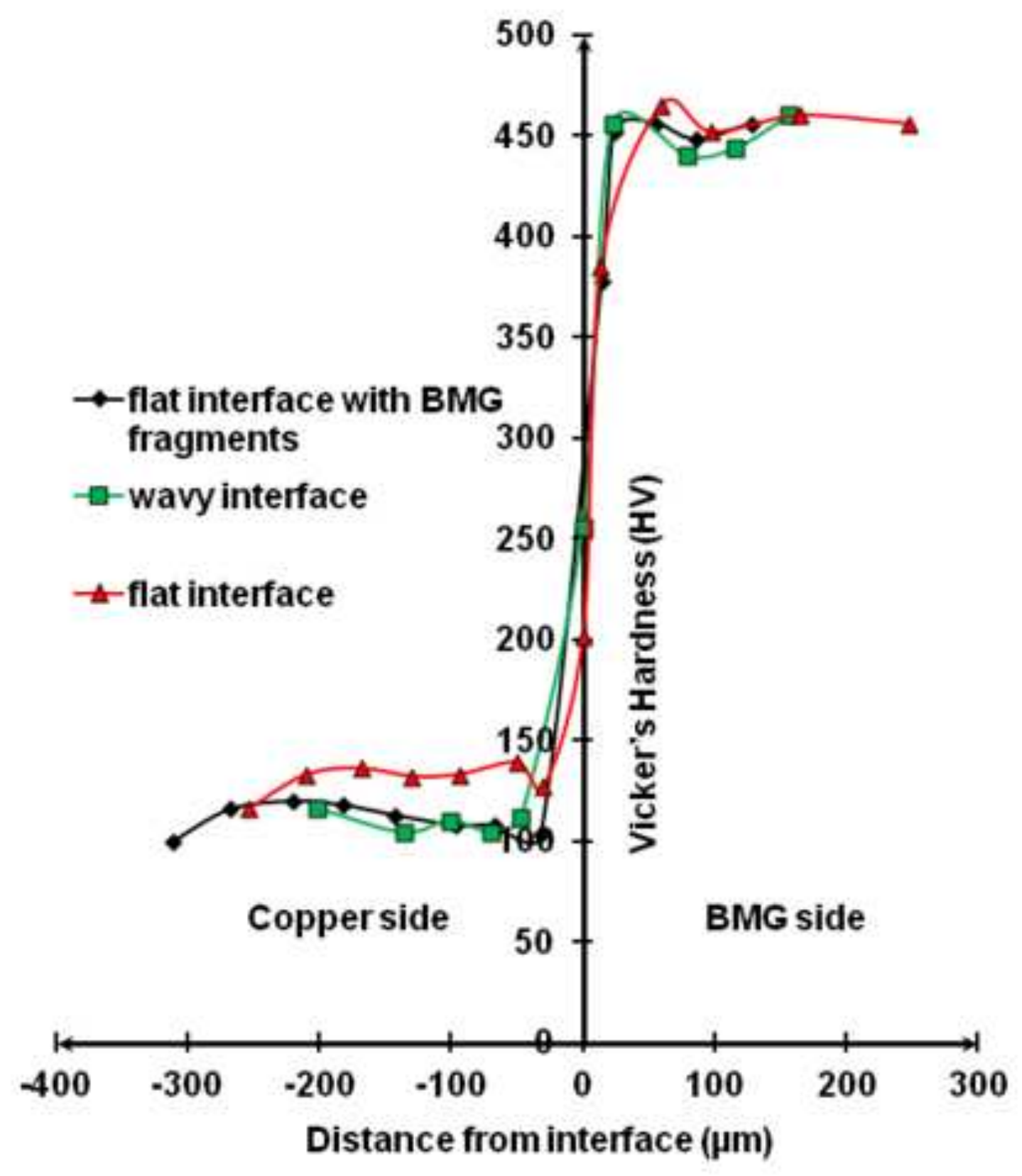


(a)

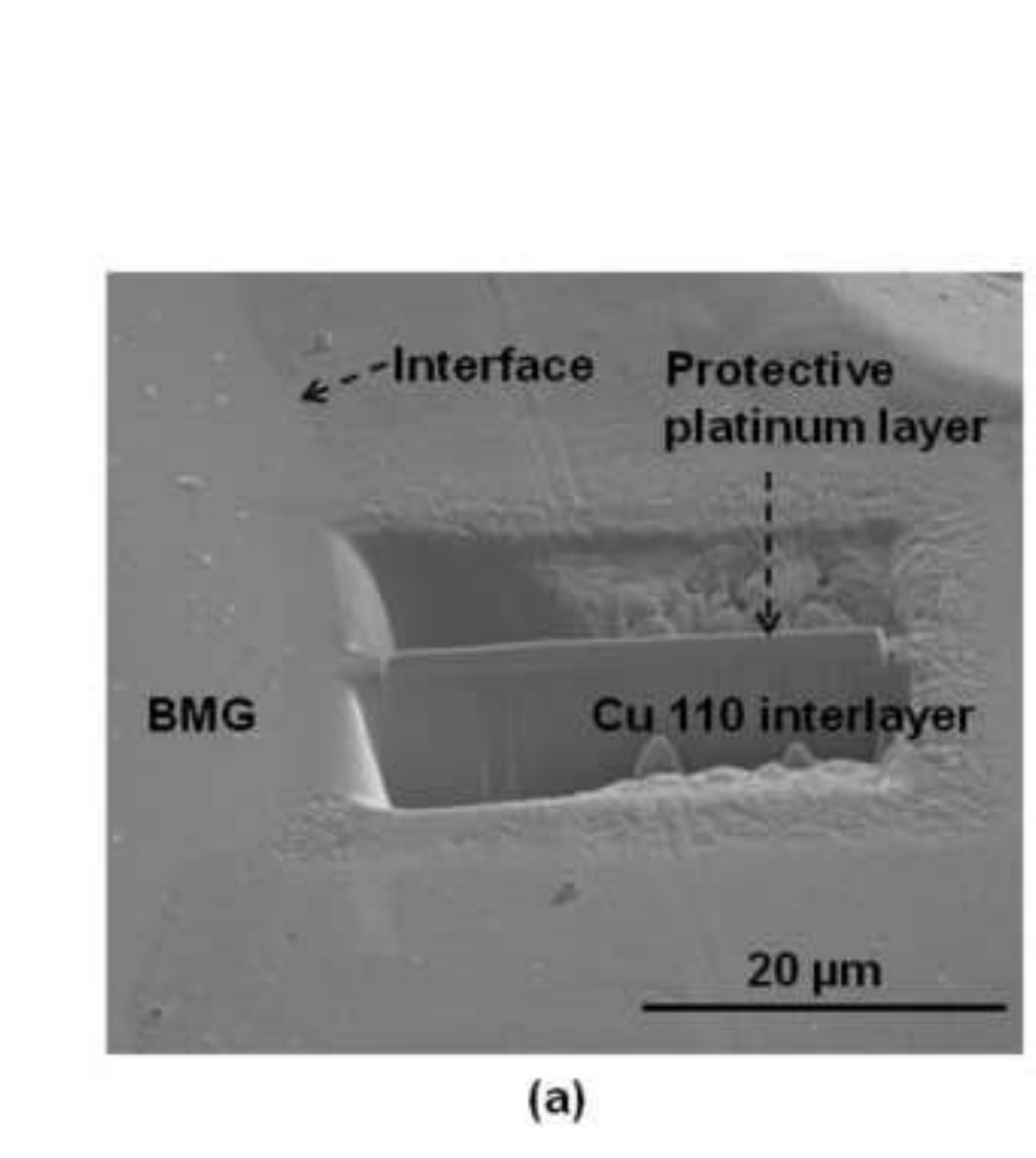

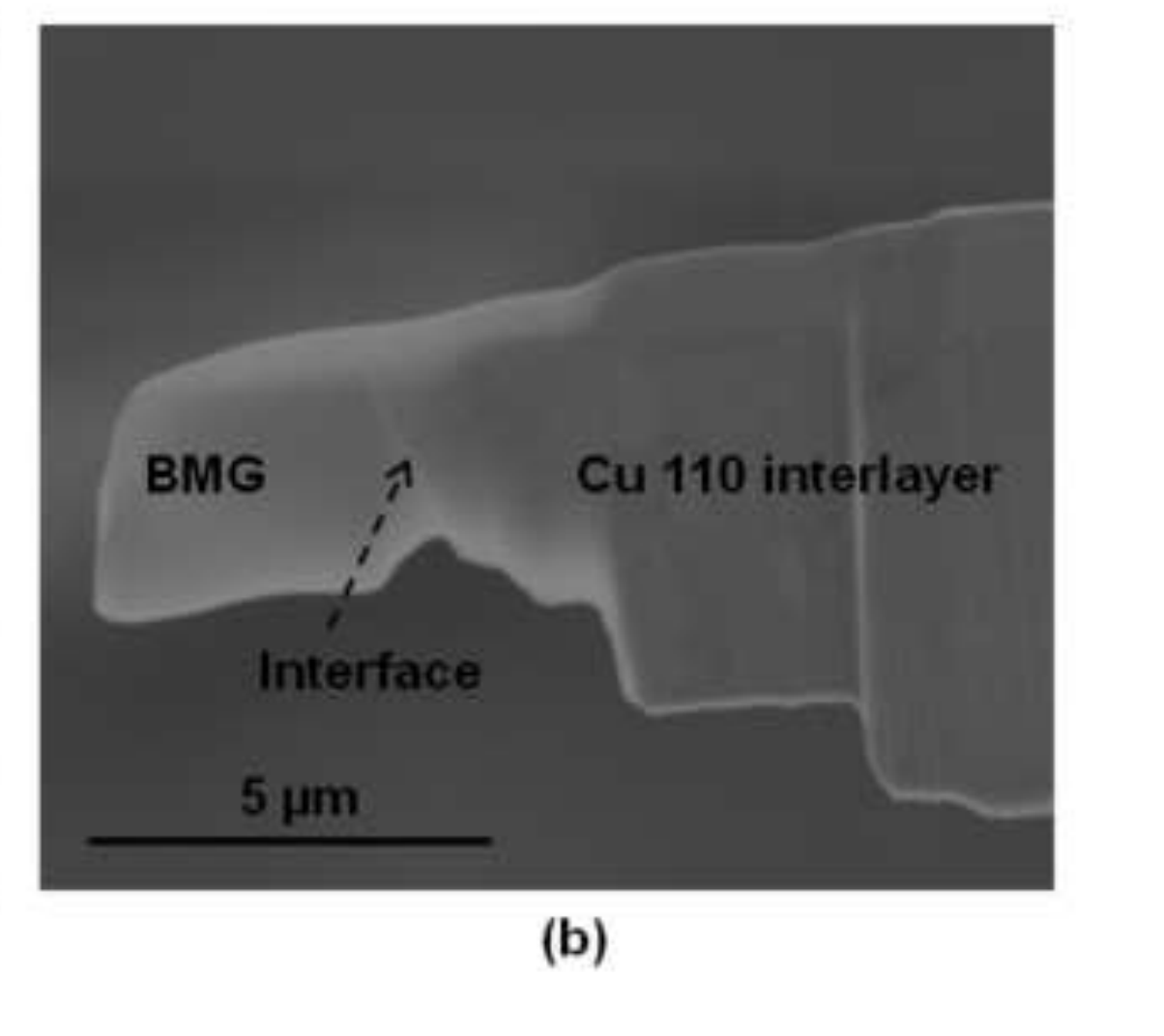

(b)

(
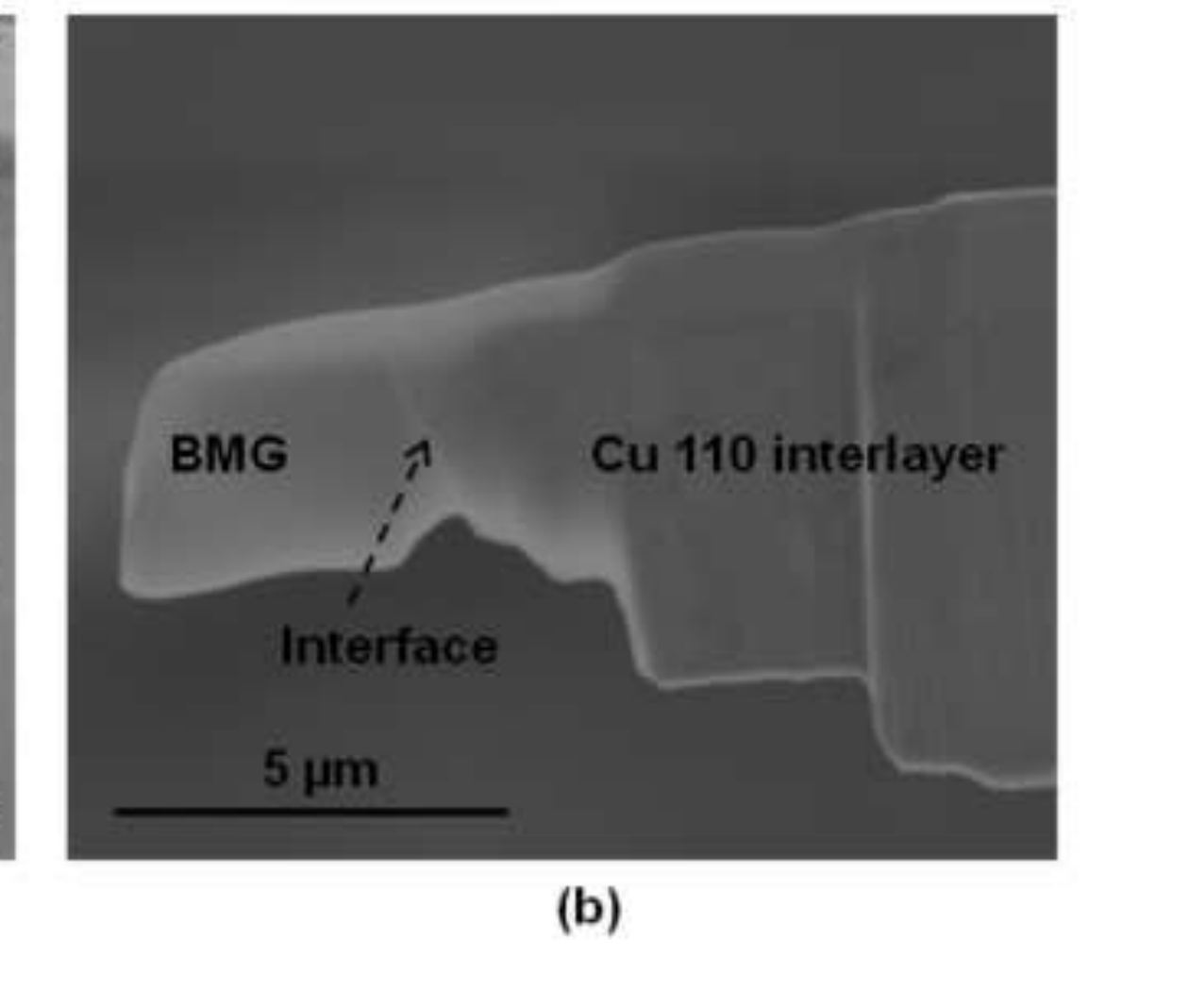

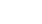

(

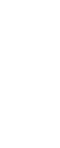
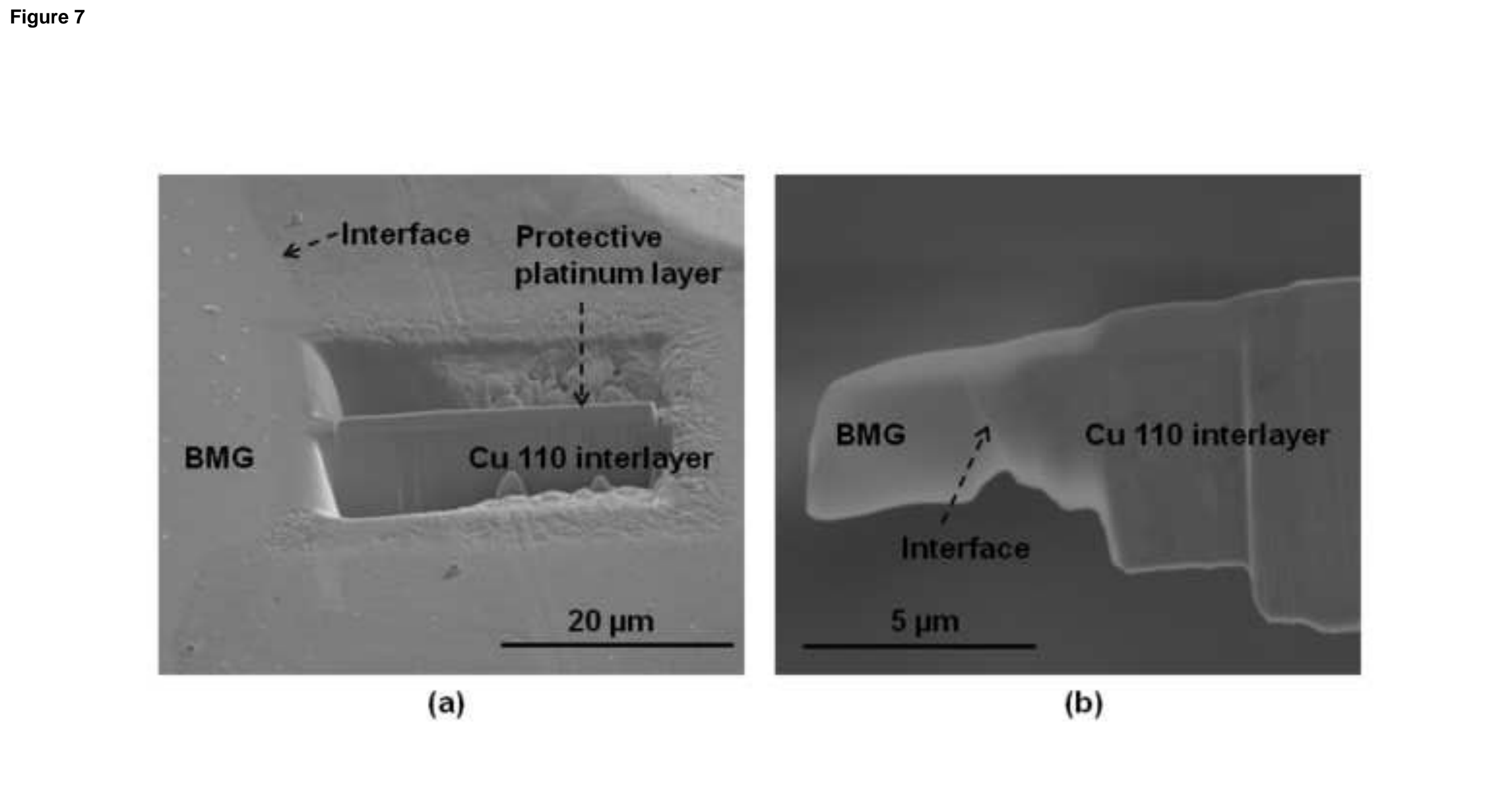

a)




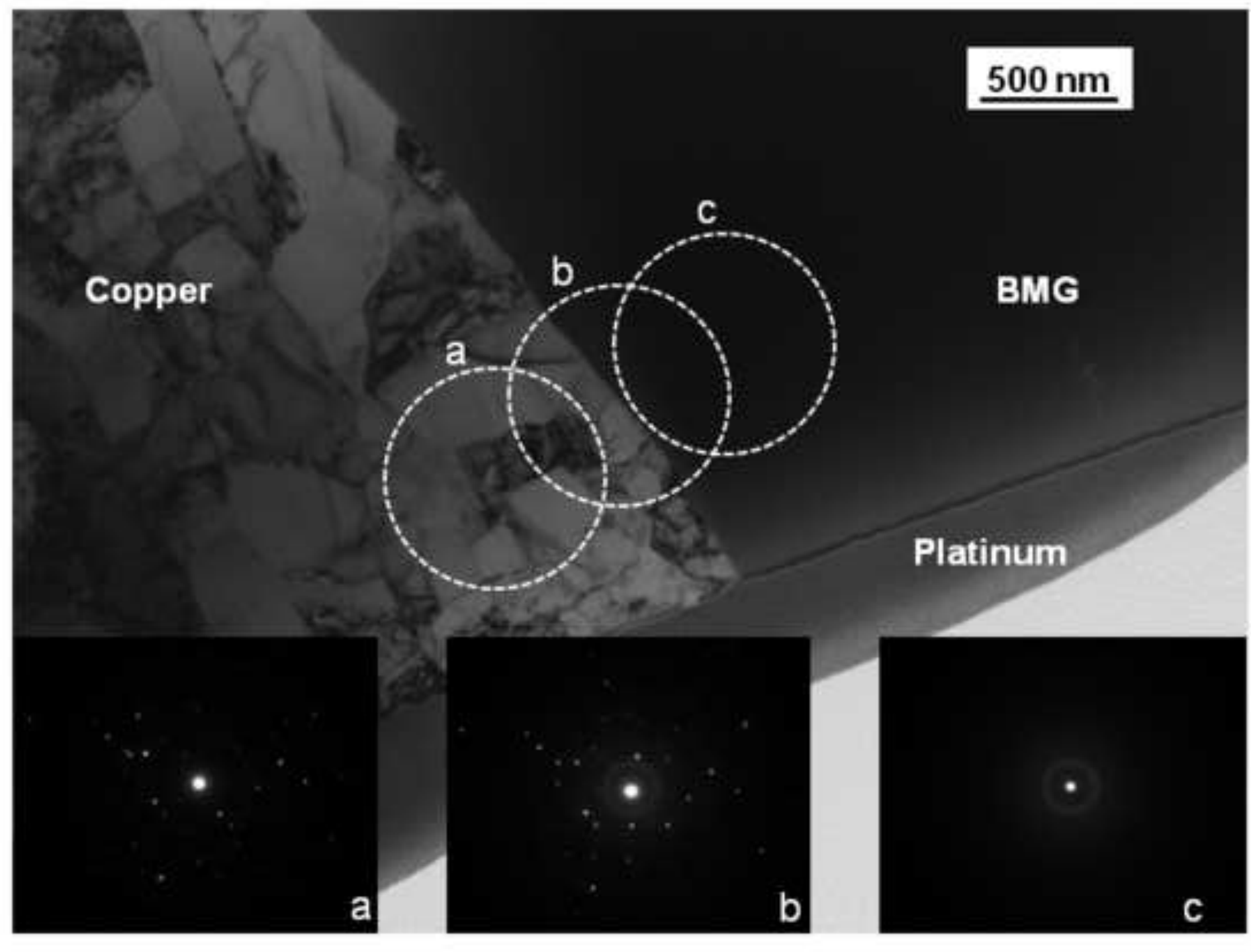

Copper 


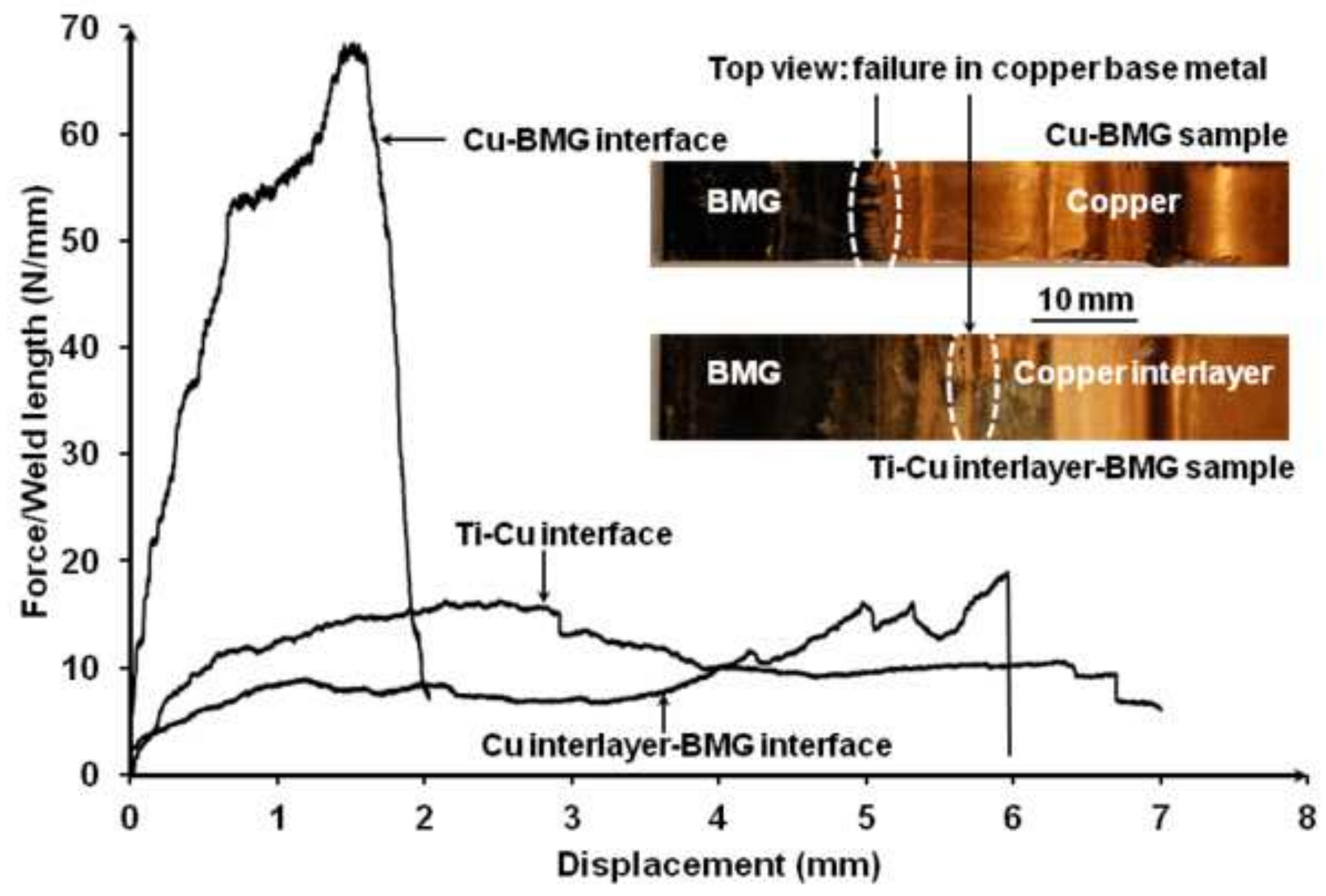

